\title{
A Fuzzy Clustering Method for Enterprise Knowledge Creation Enablers Measurement
}

\author{
Yunpeng $\mathrm{Wu}$ \\ Information Science Academy, China Electronics Technology Group Corporation, China
}

\begin{abstract}
We induce enablers of knowledge creation capability from five different aspects through analyzing process of knowledge creation. After that, by applying the fuzzy set theory and fuzzy clustering approach to analyze these enablers, a method based on fuzzy clustering is proposed. Using this method, the enterprise can find out the key attribute set of enablers which decide its enterprise knowledge creation capability can be deduced. Enterprises can adjust their strategies of knowledge management (KM) and knowledge creation according to the analytical result to improve its knowledge creation capability and gain core competence.
\end{abstract}

Keywords-knowledge creation capability; fuzzy clustering; classification rule

\section{INTRODUCTION}

In recent years, knowledge management has gained much attention by both the scholars and the enterprises. Knowledge is actually a course that when the organizations are facing up to the progressively discontinuous changes from circumstances and are compelled to improve the adaptation capability, productivity and competence, they try to combine the capability that they process data and information with IT with the capability that organizational members do creation and reformation [1]. In general, knowledge obtaining, transfer and innovation are the main activities of KM, as well as knowledge creation is the final aim of knowledge obtaining and transfer. Knowledge creation is the process that an enterprise creates and possesses the new knowledge, which is the core power for enterprises existence and development [2]. Enterprise knowledge creation activities mainly depend on knowledge creation from employees. Enterprise provides creating environment and related fundamental knowledge resource and fulfill the systematization course of individual knowledge creation. So, the enterprise knowledge creation capability (KCC) is decided by both individual KCC and the capability of enterprise's supporting and managing knowledge creation activities. Among literatures of knowledge creation, most of them mainly focus on knowledge creation theory and applications of knowledge creation method. In this paper, we induce the enablers of knowledge creation of enterprises from five aspects through analyzing the process of enterprise knowledge creation, and then apply the fuzzy set theory and fuzzy clustering method to the analysis of enterprise KCC.

\section{THE ENABLERS OF ENTERPRISE KCC}

According to the above analysis, we define $\mathrm{KCC}$ is the capability that the enterprise absorbs, transfers, learns and applies knowledge on the basis of the existing knowledge base and $\mathrm{KM}$ environment. We divide enterprise $\mathrm{KCC}$ into five aspetcs.
Possessing knowledge is the premise to create knowledge, for knowledge creation is the process that enterprise discovers and accumulates knowledge by using existing knowledge. The enterprise knowledge store is the results of the knowledge accumulation and it can be sorted into the follows: the knowledge carried by people; the knowledge carried by substantial; the knowledge carried by organizational structure; the knowledge carried by market.

Knowledge absorbing capability is the capability that the enterprise absorbs external knowledge. Enterprise knowledge creation is based on a mass of knowledge store, most of which come from exterior. Knowledge absorbing capability mainly embodies the capability to absorb and amend knowledge and the capability to utilize resource and networks.

Knowledge transferring capability is the capability that knowledge inter-transfers and sublimes in different organizational levels. Crossan presented four transforming courses including intuition, interspersion, integration and institution [3]. Therefore, enterprise knowledge transferring capability shows as intuition capability, interpretation capability, integration capability and institution capability.

The capability of knowledge learning and application will strength capability of knowledge creation, because knowledge roots in learning by which people's thinking patterns can be changed. Enterprise could absorb new knowledge and information continuously to enhance KCC. Enterprise learning capability shows as organizational training capability, organizational consultation capability, employee learning ability and organizational learning ability [4].

Knowledge creation activities, especially the creation of tacit knowledge, primarily accomplish in the fundamental environment of $\mathrm{KM}$ in which employees make knowledge intercourse by visible formal communication system and invisible informal one. The fundamental environment of KM includes infrastructure of information system, internal institution and culture environment, enterprise aspiration level, and leader ability of management, direction and decision [5].

By the above analysis, the factors that influence enterprise KCC mainly embody followings: knowledge store level, fundamental environment of KM, knowledge absorbing capability, knowledge learning capability and knowledge application capability (see Fig. I). 


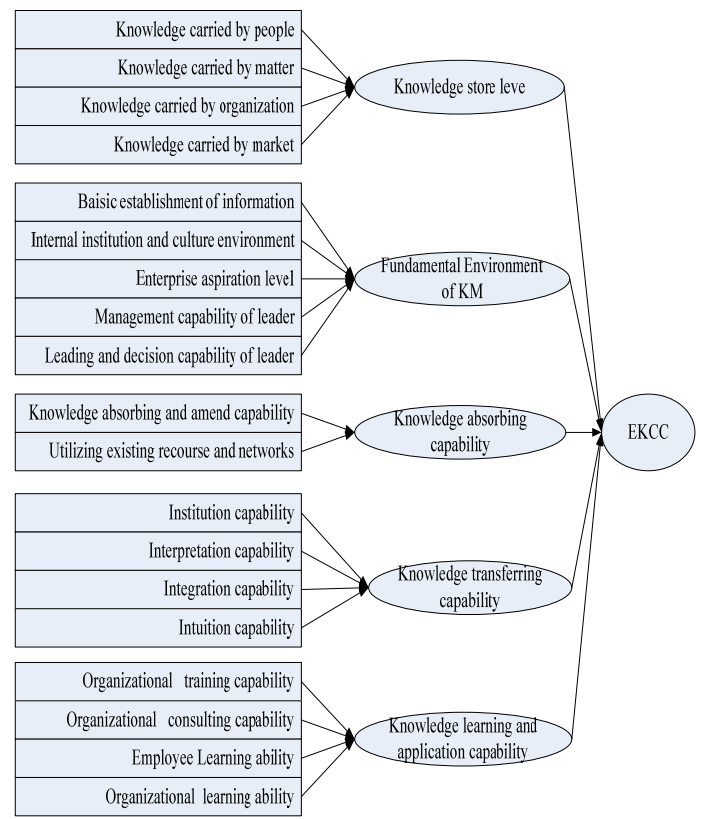

\section{FIGURE I. THE ENABLERS OF ENTERPRISE KCC}

\section{Procedures For ANALYZING ENABLERS OF KCC}

\section{A. Related Definitions}

According to rough set theory, enablers of KCC can be described as a 4-tuples $\mathrm{S}=(\mathrm{U}, \mathrm{A}, \mathrm{V}, \mathrm{f})$, and the meaning of its independent component as follows: $\mathrm{U}=\{\mathrm{u} 1, \mathrm{u} 2, \ldots, \mathrm{un}\}$ is a non-vacuous finite set which is consisted of all evaluating tuples on all factors from leaders, employees and management experts of enterprise; $\mathrm{A}=\{\mathrm{a} 1, \mathrm{a} 2, \ldots, \mathrm{am}\}$ is a non-vacuous finite set which is consisted of all attributes of enablers; $\mathrm{V}$ is a set consisted of attribute values (influencing degree) of enablers, which can be categorized into quantity attribute values and class attribute values; $f$ is a function of attribute ai and tuple uj, and the value of $f(u j$, ai) is the value of a certain tuple uj on the attribute ai.

\section{B. Determination of Key Attribute Set by Fuzzy Clustering Method}

To get the tuple set of enablers of KCC which belongs to different equivalent classes, we need to determine the key attribute set of enablers to generate classification rule of enablers. Therefore, an analytical method based on fuzzy clustering is adopted to determine the key attribute set of enablers [17]. The basic steps for fuzzy clustering analysis are as follows:

Step 1 Choose the meaningful attribute set from the complementary set to any attribute set of enablers and mark as $\bar{A}_{z}$.

Step 2 Observe a group of numerical token of attribute ai (consisted of quantity of every sort of value from k kinds of value of ai), denote as aij $(\mathrm{j}=1,2, \ldots, \mathrm{k})$, and lay out their value.

Step 3 According to the numeral token of object attribute ai and aj, adopt the least-square method, construct fuzzy similar matrix and compute its elements as follows:

$$
r_{i j}=\sum_{k=1}^{m} \min \left(a_{i k}, a_{j k}\right) / \sum_{k=1}^{m} \sqrt{a_{i k} \cdot a_{j k}}
$$

Step 4 Obtain transitive closure of fuzzy similar matrix adopting square method, namely, $[\underline{R}]_{\rightarrow}[\underline{R}]_{2 \rightarrow}[\underline{R}]_{4 \rightarrow \ldots \rightarrow}[\underline{R}]^{2^{k}}=[t(\underline{R})]$, and the matrix can be compute by the following formulation:

$\begin{array}{ccr}\text { Given } \mathrm{R}=(\mathrm{rij}) \mathrm{n} \times \mathrm{n} \text { is fuzzy similar matrix, } & \begin{array}{r}\text { then } \\ \text { where }\end{array} \\ R \circ R^{n}=(\mathrm{tij}) \mathrm{n} \times \mathrm{n} & , & \text { When }\end{array}$ $[\underline{R}]^{2^{k}} \circ[\underline{R}]^{2^{k}}=[\underline{R}]^{2^{k}}$ appears first time, the transitive closure of similar matrix $[\underline{R}]$ can be achieved and it is $[t(\underline{R})]_{=}[\underline{R}]^{2^{k}}$.

Step 5 Do clustering analysis on $[t(\underline{R})]$, by the association intensity of elements, select proper value of level set and calculate the key attribute set.

\section{The Mathematics for Discovering Classification Rule}

According to the above related definitions and the approaches for determining key attribute set, we present a method for discovering classification rule of enablers of enterprise KCC and the steps are as follows:

Step 1 Partition conclusion attribute set As off attribute set of enablers A.

Step 2 Mark the equivalent class of At as $\{\mathrm{U} 1, \mathrm{U} 2, \ldots, \mathrm{Um}\}$, Mark the equivalent class of $\mathrm{As}$ as $\{\mathrm{Y} 1, \mathrm{Y} 2, \ldots, \mathrm{Yn}\}$. Respectively describe the tuple specialty of equivalent class Ui and $\mathrm{Yj}$ as Des ( Ui ) and Des ( $\mathrm{Yj}$ ), where $\mathrm{i}=1,2, \ldots, \mathrm{m} ; \mathrm{j}=1$, $2, \ldots, n$.

Step 3 Generate classification rule of enablers. If the overlapping set of equivalent class $\mathrm{Ui}$ and $\mathrm{Yj}$ is not vacuous, then there exists the rule: $\operatorname{rij}: \operatorname{Des}(\mathrm{Ui}) \rightarrow \operatorname{Des}(\mathrm{Yj})$, where $\mathrm{i}=1$, $2, \ldots, \mathrm{m} ; \mathrm{j}=1,2, \ldots, \mathrm{n}$. If $\mathrm{Yj}$ least includes Ui ,rule rij is certain with reliability is 1 ; if $\mathrm{Yj}$ most includes $\mathrm{Ui}$, rule rij is uncertain, and its reliability is the percentage that the quantity of elements both in $\mathrm{Ui}$ and $\mathrm{Yj}$ takes the percent of the quantity of all elements of $\mathrm{Ui}$.

Step 4 Induce the achieved classification rule of enablers and get valuable analytical results of enablers of enterprise $\mathrm{KCC}$ to assist enterprise to select and adjust its decision on knowledge creation strategy.

\section{AN APPLICATION CASE}

A state-owned steel group in China wants to find out the correlative rules of enablers of KCC. The analysis help the enterprise to further find out which factors influence the implement effect of knowledge creation, by which it adjusts KM strategy to improve enterprise knowledge creation and accelerate enterprise development. This department experts 
who come from R\&D department, technology department, production department and other related departments to evaluate $\mathrm{KCC}$ and its enablers.

To simplify the question, we only adopt the evaluation results from twenty experts and only consider about the five factors in first layer, viz. knowledge store level (a1), fundamental environment of KM (a2), knowledge absorbing capability (a3), knowledge transferring capability (a4), knowledge learning and application capability (a5). Experts evaluate with fuzzy evaluation value: $\widetilde{1}$ denotes "supper good"、 $\widetilde{2}$ denotes "very good", $\widetilde{3}$ denotes "good", $\widetilde{4}$ denotes "moderate", $\widetilde{5}$ denotes "bad". They evaluate KCC (a6) with language information and get the following evaluation information:

TABLE I. THE EVALUATION INFORMATION OF ENABLERS OF KCC FROM EXPERTS

\begin{tabular}{|c|c|c|c|c|c|c|}
\hline Code & $\left(\boldsymbol{a}_{1}\right)$ & $\left(\boldsymbol{a}_{\mathbf{2}}\right)$ & $\left.\boldsymbol{( a}_{\mathbf{3}}\right)$ & $\left.\boldsymbol{( a}_{\mathbf{4}}\right)$ & $\left.\boldsymbol{( a}_{\mathbf{5}}\right)$ & $\boldsymbol{( a}_{\mathbf{6}} \mathbf{)}$ \\
\hline 1 & $\widetilde{5}$ & $\widetilde{2}$ & $\widetilde{3}$ & $\widetilde{3}$ & $\widetilde{3}$ & High \\
\hline 2 & $\widetilde{2}$ & $\widetilde{1}$ & $\widetilde{1}$ & $\widetilde{2}$ & $\widetilde{4}$ & Very High \\
\hline 3 & $\widetilde{4}$ & $\widetilde{2}$ & $\widetilde{2}$ & $\widetilde{2}$ & $\widetilde{2}$ & Very High \\
\hline 4 & $\widetilde{4}$ & $\widetilde{1}$ & $\widetilde{1}$ & $\widetilde{3}$ & $\widetilde{1}$ & Very High \\
\hline 5 & $\widetilde{4}$ & $\widetilde{2}$ & $\widetilde{1}$ & $\widetilde{2}$ & $\widetilde{4}$ & Very High \\
\hline 6 & $\widetilde{4}$ & $\widetilde{2}$ & $\widetilde{3}$ & $\widetilde{3}$ & $\widetilde{3}$ & High \\
\hline 7 & $\widetilde{3}$ & $\widetilde{2}$ & $\widetilde{1}$ & $\widetilde{2}$ & $\widetilde{3}$ & Very High \\
\hline 8 & $\widetilde{4}$ & $\widetilde{2}$ & $\widetilde{3}$ & $\widetilde{4}$ & $\widetilde{2}$ & Moderate \\
\hline 9 & $\widetilde{3}$ & $\widetilde{2}$ & $\widetilde{2}$ & $\widetilde{2}$ & $\widetilde{2}$ & Very High \\
\hline 10 & $\widetilde{2}$ & $\widetilde{2}$ & $\widetilde{2}$ & $\widetilde{2}$ & $\widetilde{3}$ & Very High \\
\hline 11 & $\widetilde{3}$ & $\widetilde{1}$ & $\widetilde{2}$ & $\widetilde{2}$ & $\widetilde{3}$ & Very High \\
\hline 12 & $\widetilde{4}$ & $\widetilde{3}$ & $\widetilde{3}$ & $\widetilde{3}$ & $\widetilde{3}$ & High \\
\hline 13 & $\widetilde{4}$ & $\widetilde{3}$ & $\widetilde{2}$ & $\widetilde{3}$ & $\widetilde{3}$ & High \\
\hline 14 & $\widetilde{4}$ & $\widetilde{2}$ & $\widetilde{2}$ & $\widetilde{4}$ & $\widetilde{2}$ & High \\
\hline 15 & $\widetilde{4}$ & $\widetilde{3}$ & $\widetilde{3}$ & $\widetilde{3}$ & $\widetilde{3}$ & High \\
\hline 16 & $\widetilde{5}$ & $\widetilde{2}$ & $\widetilde{3}$ & $\widetilde{4}$ & $\widetilde{3}$ & Moderate \\
\hline 17 & $\widetilde{4}$ & $\widetilde{2}$ & $\widetilde{3}$ & $\widetilde{3}$ & $\widetilde{3}$ & High \\
\hline 18 & $\widetilde{4}$ & $\widetilde{1}$ & $\widetilde{2}$ & $\widetilde{3}$ & $\widetilde{4}$ & High \\
\hline 19 & $\widetilde{3}$ & $\widetilde{2}$ & $\widetilde{1}$ & $\widetilde{3}$ & $\widetilde{1}$ & Very High \\
\hline 20 & $\widetilde{4}$ & $\widetilde{2}$ & $\widetilde{3}$ & $\widetilde{3}$ & $\widetilde{3}$ & High \\
\hline
\end{tabular}

We can get the 4-tuples of evaluation information, namely, $\mathrm{A}=\{\mathrm{a} 1, \mathrm{a} 2, \mathrm{a} 3, \mathrm{a} 4, \mathrm{a} 5, \mathrm{a} 6\} ; \mathrm{V}=\{\widetilde{1}, \widetilde{2}, \widetilde{3}, \widetilde{4}, \widetilde{5}$, very high, high, moderate, low $\} ; \mathrm{U}=\{\mathrm{u} 1, \mathrm{u} 2, \ldots, \mathrm{u} 20\}$, where, $\mathrm{u} 1=(\widetilde{5}, \widetilde{2}, \widetilde{3}, \widetilde{3}, \widetilde{3}$,high $)$, u2 $=(\widetilde{2}, \widetilde{1}, \widetilde{1}, \widetilde{2}, \widetilde{4}$, very high),.., u20 $=(\widetilde{4}, \widetilde{2}, \widetilde{3}, \widetilde{3}, \widetilde{3}$,high $) ; \mathrm{f}(\mathrm{u} 1, \mathrm{a} 1)=\widetilde{5}$, $f(u 1, a 2)=\widetilde{2}, f(u 1, a 3)=\widetilde{3}, f(u 1, a 4)=\widetilde{3}, f(u 1, a 5)=\widetilde{3}$,

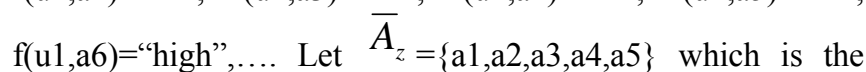
complementary set of conclusion attribute set $\mathrm{A}=\{\mathrm{a} 6\}$. From
Table 1 , we can get the numerical token aij $(j=1,2,3,4,5)$ about attribute ai $(i=1,2,3,4,5)$.

Compute similar matrix $[\underline{R}]$ and its transitive closure $[t(\underline{R})]$ with (1)

$$
\begin{gathered}
{[\underline{R}]=\left[\begin{array}{ccccc}
1 & 0.58 & 0.64 & 0.56 & 0.58 \\
0.58 & 1 & 0.74 & 0.67 & 0.57 \\
0.64 & 0.74 & 1 & 0.94 & 078 \\
0.56 & 0.67 & 0.94 & 1 & 0.91 \\
0.58 & 0.57 & 0.78 & 0.91 & 1
\end{array}\right]} \\
{[t(\underline{R})]=\left[\begin{array}{ccccc}
1 & 0.64 & 0.64 & 0.64 & 0.64 \\
0.64 & 1 & 0.74 & 0.74 & 0.74 \\
0.64 & 0.74 & 1 & 0.94 & 0.91 \\
0.64 & 0.74 & 0.94 & 1 & 0.91 \\
0.64 & 0.74 & 0.91 & 0.91 & 1
\end{array}\right]}
\end{gathered}
$$

To make the association intensity as large as possible, we take $\lambda \geq 0.94$, then $\bar{A}_{z}$ can be sorted into four classes, viz. $\{\mathrm{a} 1\},\{\mathrm{a} 2\},\{\mathrm{a} 3, \mathrm{a} 4\},\{\mathrm{a} 5\}$, and key attribute set is $\{\mathrm{a} 3, \mathrm{a} 4\}$. $\mathrm{Az}=\{\mathrm{a} 6\}$ is a conclusion attribute, so the key attribute is $\{a 3, a 4\}$. From that, we can get classification rule: (1) based on the tuple value of conclusion attribute set $A z=\{a 6\}$, we can sort As into four classes: Y1、Y2、Y3 and Y4. Let them be "very high"、"high"、 "moderate" and "low" respectively, where $\mathrm{Y} 1=\{\mathrm{u} 3, \mathrm{u} 4, \mathrm{u} 5, \mathrm{u} 7, \mathrm{u} 9, \mathrm{u} 10, \mathrm{u} 11, \mathrm{u} 19\}, \mathrm{Y} 2=\{\mathrm{u} 1, \mathrm{u} 6, \mathrm{u} 12, \mathrm{u} 13$, $\mathrm{u} 14, \mathrm{u} 15, \mathrm{u} 17, \mathrm{u} 18, \mathrm{u} 20\}$ and $\mathrm{Y} 3=\{\mathrm{u} 8, \mathrm{u} 16\}$. (2) based on the tuple value of key attribute set $\{\mathrm{a} 3, \mathrm{a} 4\}$, At, we can sort At into seven classes : $\mathrm{U} 1=\{\mathrm{u} 2, \mathrm{u} 5, \mathrm{u} 7\}, \quad \mathrm{U} 2=\{\mathrm{u} 4, \mathrm{u} 19\}$, $\mathrm{U} 3=\{\mathrm{u} 3, \mathrm{u} 9, \mathrm{u} 10, \mathrm{u} 11\}, \quad \mathrm{U} 4=\{\mathrm{u} 13, \mathrm{u} 18\}, \quad \mathrm{U} 5=\{\mathrm{u} 14\}$, $\mathrm{U} 6=\{\mathrm{u} 1, \mathrm{u} 6, \mathrm{u} 12, \mathrm{u} 15, \mathrm{u} 17, \mathrm{u} 20\}$ and $\mathrm{U} 7=\{\mathrm{u} 8, \mathrm{u} 16\}$.

When take Ui $(i=1,2, \ldots, 7)$ as classing conditions and $\mathrm{Yj}$ $(j=1,2,3)$ as classing conclusion, we will get the classification rule as follows: high"

$$
\mathrm{R} 1:(\mathrm{a} 4=(\tilde{1} \vee \tilde{2})) \vee(\mathrm{a} 4=\widetilde{3} \wedge \mathrm{a} 3=\tilde{1}) \Rightarrow \text { a6="very }
$$

$$
\begin{gathered}
\mathrm{R} 2:(\mathrm{a} 4=\tilde{3}) \vee(\mathrm{a} 4=\tilde{4} \wedge(\mathrm{a} 3=\tilde{1} \vee \tilde{2})) \Rightarrow \mathrm{a} 6=\text { "high" } \\
\mathrm{R} 3:(\mathrm{a} 4=\tilde{4}) \wedge(\mathrm{a} 3=\tilde{3}) \Rightarrow \mathrm{a} 6=" \text { moderate" } \\
\text { V. CONCLUSION }
\end{gathered}
$$

The analysis of enablers of enterprise KCC provides important instrument for enterprise, which helps enterprise to know, hold and analyze the nature and rule of this creative activity and to describe it systemically and scientifically in quantity. At the same time, the analysis means much to establish new knowledge creation policy and new strategy of innovation, enhancing capability and level of knowledge creation, improving work of innovation management, releasing uncertainness of knowledge creation and so on. This paper presented a method based on fuzzy clustering for analyzing enablers of $\mathrm{KCC}$, which is easy to understand and command, 
further extending knowledge creation theory and application in enterprise.

\section{REFERENCES}

[1]. Yogesh M., , 1998 , Knowledge management for the new world of business, Asia Strategy Leadership Institute Review, 6, 58-60.

[2]. Choi B., Lee H., 2002, Knowledge management strategy and its link to knowledge creation process, Expert Systems with Applications, 23, 173-187.

[3]. Chou S.W., He M.Y., 2004, Facilitating Knowledge Creation by Knowledge Assets, Proceedings of the 37th Hawaii International Conference on System Sciences.

[4]. Hoegl M., Schulze A., 2005, How to Support Knowledge Creation in New Product Development: An Investigation of Knowledge Management Methods, European Management Journal, 23, 263-273.

[5]. Lindermana K., Schroedera R.G., Zaheer S., 2004, Integrating quality management practices with knowledge creation processes, Journal of Operations Management, 22, 589-607. 